\title{
Effect of climate change on rice yield at Kharagpur, West Bengal
}

\author{
Tanmoyee Bhattacharya ${ }^{1}$, Dr. R.K Panda ${ }^{2}$ \\ ${ }^{1}$ M.Tech, Agriculture and Food engineering Department, Indian Institute of Technology, Kharagpur, West \\ Bengal, India \\ ${ }^{2}$ Professor, Agriculture and Food engineering Department, Indian Institute of Technology, Kharagpur, West \\ Bengal, India
}

\begin{abstract}
The daily rainfall and temperature data (1977-2007) of Kharagpur were analyzed to know seasonal and annual variability. The monsoon season June-September was characterized for seasonal trends. FAO Aquacrop model version 3.1 was tested to understand the response of rice to temperature, $\mathrm{CO}_{2}$, water and to simulate the grain yield of rice under various independent data sets. The inter-annual variability and trends of monthly maximum, minimum, mean temperatures and rainfall for the crop growing season had been analyzed. The results showed that there was decrease in yield with per ${ }^{\circ} \mathrm{C}$ increase in temperature and increase in yield with per mm increase in rainfall in Subtropical region. The results of the study revealed that the grain yield increased an average of $0.35 \mathrm{~kg} / \mathrm{ha}$ with per mm increase in rainfall and decreased by $156.2 \mathrm{~kg} / \mathrm{ha}$ per degree rise in mean temperature at that region. The simulation study had also conducted under different temperature, rainfall scenarios and $\mathrm{CO}_{2}$ concentration. The most negative scenario was $T_{\max } 4^{\circ} \mathrm{C}+T_{\min } 4^{\circ} \mathrm{C}+50 \mathrm{ppm} \mathrm{CO}_{2}$ (grain yield reduced by $8.31 \%$ ) and $T_{\max } 4^{\circ} \mathrm{C}+T_{\min } 4^{\circ} \mathrm{C}+(P-10) \mathrm{mm}$ (grain yield reduced by $37.67 \%$ ).
\end{abstract}

Keywords - Aquacrop v3.1, Climate variability, temperature, trend, rainfall, yield

\section{INTRODUCTION}

Climate change is taking place all over the world and India is of no exception. The agricultural sector is a driving force in the gas emissions and land use effects that causes climate change. (Ahmad et al., 2011) Agriculture is always vulnerable to unfavorable weather events and climate conditions. The study of precipitation trends is critically important for a country like India whose food security and economy are dependent on the timely availability of water. The all India mean annual surface temperature based on 73 stations showed a significant warming of $0.4^{\circ} \mathrm{C}$ (Hingane et al., 1985).over past 100 years. It is likely that the currently observed trend of global warming, which has been $0.6^{\circ} \mathrm{C} \pm 0.2$ since 1900 , will continue and the average global temperature will increase between $1.4^{\circ} \mathrm{C}$ to $5.8^{\circ} \mathrm{C}$ over the period 1990 to 2100 (Houghton et al., 2001). The impact of climate change on agriculture food production is of global concerns. After an increase of $0.74^{\circ} \mathrm{C}$ during the last century, globally averaged surface temperature is expected to rise between $1.1^{\circ} \mathrm{C}$ up to $6.4^{\circ} \mathrm{C}$ by the last decade of the $21 \mathrm{st}$ century. This temperature increase will alter the timing and amount of rainfall. Increments in both maximum and minimum temperature by $4^{\circ} \mathrm{C}$ decreased rice yield by $34 \%$ as compared to base scenario with current weather data (Amgain et al., 2006). The Indian economy largely depends on agriculture which is highly influenced by the spatio-temporal variability of precipitation. Kharif and rabi are the two main crop-growing seasons which require major proportion of rainfall. Increase in heavy precipitation events, however, can have adverse effects on the crops (Revadekar et al., 2011). Rice (Oryza sativa L.) is the staple food for more than two-third of the world's population. Stable and high yields of rain fed lowland rice are important for food security in many of the subsistence farming system in Asia (Cooper, 1999). Phonological development of plants is generally related to temperature. At higher temperature crops develop faster and their potential production will be generally lower (this does not apply to plants that are mainly photoperiod sensitive). Rain fed rice production is largely dependent on the supply of water during rainy monsoon season, with the timing and amount of rainfall playing a critical role. An early arrival of the monsoon and excessive rainfall can cause flooding, which is harmful to young rice seedlings. On the other hand, a late arrival usually leads to severe water stress. Ample rainfall during growing season is also essential for attaining optimum yield. Often variability of rainfall during the monsoon season results in severe flooding and loss of crops. To overcome the loss of crops during flooding, farmers occasionally re-plant rice seedlings in an attempt to avoid food shortages. Crop models are generally designed to operate at the field level, and they rely on detailed field- scale inputs such as the soil, plant genotype and weather, to predict yield and other crop variables at that scale. FAO Aquacrop model version 3.1 was tested using independent datasets to simulate the biomass and grain yield under various inputs and planting dates. (Habtu et al., 2010).FAO Aquacrop model was used to predict crop productivity, water requirement and water use efficiency (WUE) under water limiting conditions (Heng et al., 2009). 


\section{Objective}

1. Analyzing inter-annual variability and trends of monthly temperature and rainfall (June - September).

2. Studying impact of climate change on yield response of rice using Aquacrop v.3.1 software.

\section{MATERIAL AND METHODS}

The climate of Kharagpur $\left(22.33^{\circ} \mathrm{N}\right.$ latitude and $87.33^{\circ} \mathrm{E}$ longitude) classified as sub-humid, subtropical. It receives an average rainfall of $1200 \mathrm{~mm}$ with an occurrence of $70-75 \%$ of the total rainfall in the monsoon during June to October and the average temperature varies between $21{ }^{\circ} \mathrm{C}$ and $32{ }^{\circ} \mathrm{C}$. The basic data used in this study was site weather data (maximum temperature, minimum temperature, evapotranspiration and rainfall) for the period 1977-2007 collected from Indian Meteorological Department, Pune, soil data as well as management and experimental data. By default Aquacrop obtains the atmospheric $\mathrm{CO}_{2}$ concentration for a particular year from the 'MaunaLoa. $\mathrm{CO}_{2}$ ' file in its database which contains observed and expected concentrations at Mauna Loa Observatory. The daily maximum temperature, minimum temperature and rainfall was analyzed (Fig.1. and Fig.2.) during the crop growing season (June-September). The crop data included days from sowing to emergence, full cover date, maturity date, and harvest date, start of senescence date, maximum rooting date, and maximum root depth. The data on grain yield was recorded at different stages of crop growth during each crop experiment. Soil water in Aquacrop v 3.1 which is a soil water balance as well as crop growth simulation model was calibrated using the measured data set of 1998 whereas it was validated using 1999 datasets. The validation of the model for grain yield was done using independent data sets of the cropping seasons of 1998 (rain fed and irrigated, planted on June 21); 1999 (rain fed and irrigated, planted on June 11) and 2000 (rain fed and irrigated, planted on June 10). Calibration and validation of the model requires Site weather data (latitude and longitude of the weather station, daily values of rainfall $(\mathrm{mm})$, maximum, minimum air temperature $\left({ }^{\circ} \mathrm{C}\right)$, evapotranspiration, Site soil data, Management and experimental data for the experiment. Aquacrop requires more than 10 parameters known as "conservative parameters", "cultivar specific parameters", "parameters dependent on environment or management". There are six cultivar specific genetic coefficients. They affect development rates, organ growth and plant ontology. These coefficients are constant in the model and are used to quantify differences in growth and development responses between different rice cultivars.

An informative way to illustrate the main aspects of the temperature data box plot was used in this study (Fig: 1). The upper and lower hinge of the box indicates the 75th percentile and 25th percentile of the data set, respectively. The line in the box indicates the median value of the data set. The ends of the vertical lines indicate the minimum and maximum values. The general shape of the plot is the same, but the 'odd' large value stands out and therefore deserves closer scrutiny. An additional use of box plots was also done to show outliers. Fig 2 indicates the cumulative rainfall during the growth period of rice at Kharagpur for the years 1977-2007.

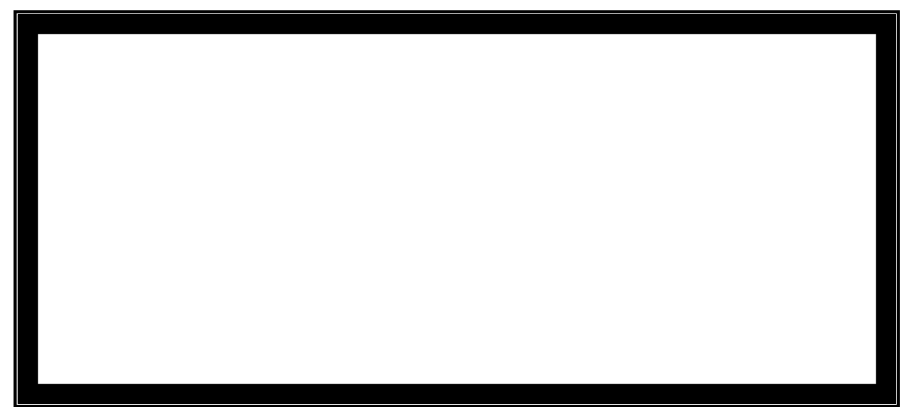

Fig.1. Variation in maximum, minimum and mean temperatures at Kharagpur during the growth period of rice for the years 1977-2007.

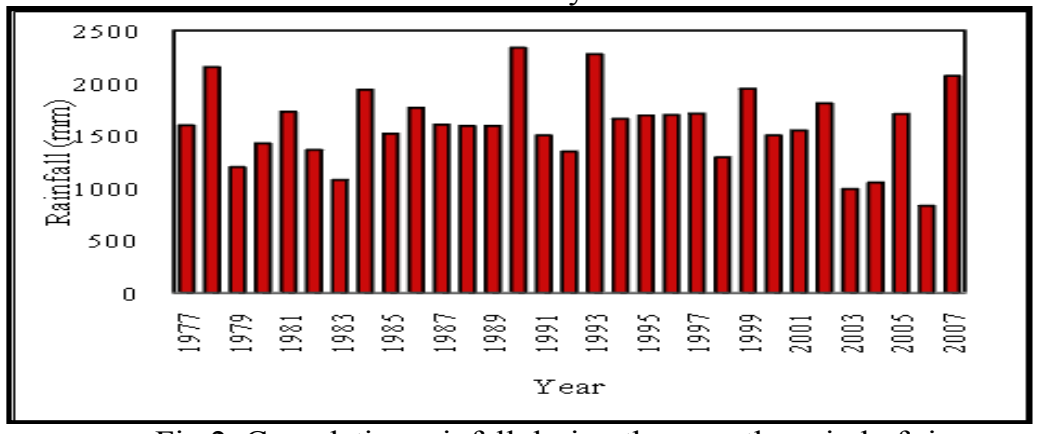

Fig.2. Cumulative rainfall during the growth period of rice 


\section{RESULT AND DisCUSSIONS}

The general statistical features of temperature from June-December are given in Table1. Standard deviation (represented by the symbol sigma, $\sigma$ ) shows how much variation or dispersion exists from the average or expected value. A low standard deviation indicates that the data points tend to be very close to the mean; high standard deviation indicates that the data points are spread out over a large range of values. The standard deviation is much higher for maximum temperature $T_{\max }$ to minimum temperature $\mathrm{T}_{\min }$ for the monsoon months at Kharagpur (1977-2007). This indicates that there is much variation of maximum temperature compared to minimum temperature. The years 1978, 1984, 1990, 1993 and 2007 had strong positive anomaly of monsoon rainfall which was close to or higher than $+\sigma$. The monsoon rainfall for Kharagpur shows a very weak decreasing trend at the rate of $2.2 \mathrm{~mm} /$ day. The figure shows that the monsoon rainfall has a complicated nature of variation. The impact of such variations on the rice yield is complex. The years 1983, 2003, 2004, had been identified as the drought years with rainfall anomalies equal to or lower than $-\sigma$. Since there is no much of trends in the rainfall, the inter-annual variability would mainly be responsible for the climatic impacts on the variation of rice yield. Fig. 5 shows the standard deviation $(\sigma)$ obtained by using 31 years rainfall data for Kharagpur which indicates that the variability of monsoon rainfall exhibits decreasing trend during the whole period . Statistical analysis was performed to evaluate the performance of Aquacrop model in simulating crop variables. The statistical analysis result given in Table 3 and Fig 6 indicated that the model simulated grain yield efficiency reasonably well. The model was calibrated using the experimental data on grain yield, actual evapotranspiration and water use efficiency. The well watered treatment (rice field with $50 \mathrm{~mm}$ weir height) of each experiment was selected for calibration. The values of genetic coefficients were estimated using the best fit method. The best set of genetic coefficients was obtained by trial and error method. All the genetic coefficients have a preassigned range and calibrated values needs to fall within this range. A fairly good agreement was found between simulated and measured grain yield of rice. It also found that the simulated and measured yield, actual evapotranspiration and water use efficiency were matching reasonably well with each other. The model was validated for rain fed and irrigates conditions using all the three years of field experiments during 19982000. The genetic coefficients (Table 2) determined by the process of calibration were used for validation. For validation, the model was run independently for rain fed and irrigated conditions. The time series of mean temperature for the rice growing season also exhibits a positive trend with a slope of $0.019^{\circ} \mathrm{C}$ at Kharagpur (Fig 3).Fig. 4 shows the temporal distribution of total monsoon rainfall for June-September, which depicts that the rainfall exhibits inter-annual variations in the time scale of 31 years with standard deviation $(\sigma)$ of $344.88 \mathrm{~mm}$ at Kharagpur. It was observed that the yield anomalies varied in opposite phase compared to the mean temperature .Yield-temperature response curves (Fig 7) show that there is a decrease in grain yield of rice in seasonal temperature. Grain yield decreased by $156.2 \mathrm{~kg} / \mathrm{ha}$ per degree rise in mean temperature.

The rice requires a few centimeter of flooding in its root zone for normal growth and good yield. In general, the deficit rainfall caused droughts affecting the vegetative growth as well as reproductive process of rice crops, but an excess rainfall damaged the crops through devastating and long-lasting floods (Quadir et al.2007; Choudhury et al. 2003). The Fig.8 shows the distribution of annual rainfall for the monsoon season and the corresponding anomalies of rice yield at Kharagpur. Yield-rainfall response curves show that there is a increase in grain yield of rice with increase in rainfall. At Kharagpur it was observed that there was a slight increase in grain yield of rice per mm rise in annual rainfall. Grain yield increased by $0.51 \mathrm{~kg} / \mathrm{ha}$ per $\mathrm{mm}$ rise in rainfall. The years 1984, 1990, 1995 and 2007 showed strong positive anomalies of monsoon rainfall. All these years showed very high rainfall and higher rice yield. Crop model is sensitive to $\mathrm{CO}_{2}$ levels and has a positive impact on rice yield. Although higher $\mathrm{CO}_{2}$ levels in the future would balance the detrimental effects of increased temperatures to some extent but it would not be able to offset them. The simulation studies had conducted under different climatic scenarios of temperature carbon dioxide concentration and rainfall. Maximum scenarios showed the negative effect on rice production in Kharagpur. Scenario likes, $\mathrm{T}_{\max } 2^{0} \mathrm{C}+\mathrm{T}_{\min } 2^{0} \mathrm{C}+200 \mathrm{ppm}$ $(1.5 \%) \mathrm{CO}_{2}$ had some positive effect on rice production but those positive effects were not so significant compared to negative effect of other scenarios. The most significant negative effect scenario was $\mathrm{T}_{\max } 4^{0} \mathrm{C}+\mathrm{T}_{\min }$ $4^{0} \mathrm{C}+50 \mathrm{ppm} \mathrm{CO}_{2}(-8.31 \%)$. The various scenarios and their effects on rice production are shown in Figure.9. Table 4. presents yield by applying relative temperature (T) changes of $\mathrm{T}+1{ }^{\circ} \mathrm{C}, \mathrm{T}+2{ }^{\circ} \mathrm{C}$ and $\mathrm{T}+4^{\circ} \mathrm{C}$ to the monthly average series of temperature and relative precipitation $(\mathrm{P})$ changes of $\mathrm{P}-10 \%, \mathrm{P}-5 \%, \mathrm{P}+5 \%, \mathrm{P}+10 \%$ to the monthly average series of precipitation. From predicting rice yield under different scenarios, it was clear that temperature is one of the most dominant climatic factors, which affect rice production in Subtropical region significantly, and its effectiveness was very high, if it may raise $4^{0} \mathrm{C}$ and $\mathrm{CO}_{2}$ concentration $50 \mathrm{ppm}$. 
Table 1: Mean and standard deviation $(\sigma)$ of maximum temperature $\left(\mathrm{T}_{\max }\right)$ and minimum temperature $\left(\mathrm{T}_{\min }\right)$ for June-september at Kharagpur, Dumdum and Purulia. The temperature is expressed in ${ }^{\circ} \mathrm{C}$.

\begin{tabular}{|c|c|c|c|c|}
\hline Parameters & June & July & August & September \\
\hline $\left.\mathrm{T}_{\min }{ }^{\circ} \mathrm{C}\right)$ & 26 & 26.03 & 26 & 25.37 \\
\hline$\sigma$ of $\mathrm{T}_{\min }$ & 0.72 & 0.71 & 0.63 & 0.76 \\
\hline $\left.\mathrm{T}_{\max }{ }^{\circ} \mathrm{C}\right)$ & 34.29 & 32.62 & 32.40 & 32.35 \\
\hline$\sigma$ of ${ }_{\operatorname{Tmax}}$ & 1.28 & 0.80 & 0.98 & 0.89 \\
\hline
\end{tabular}

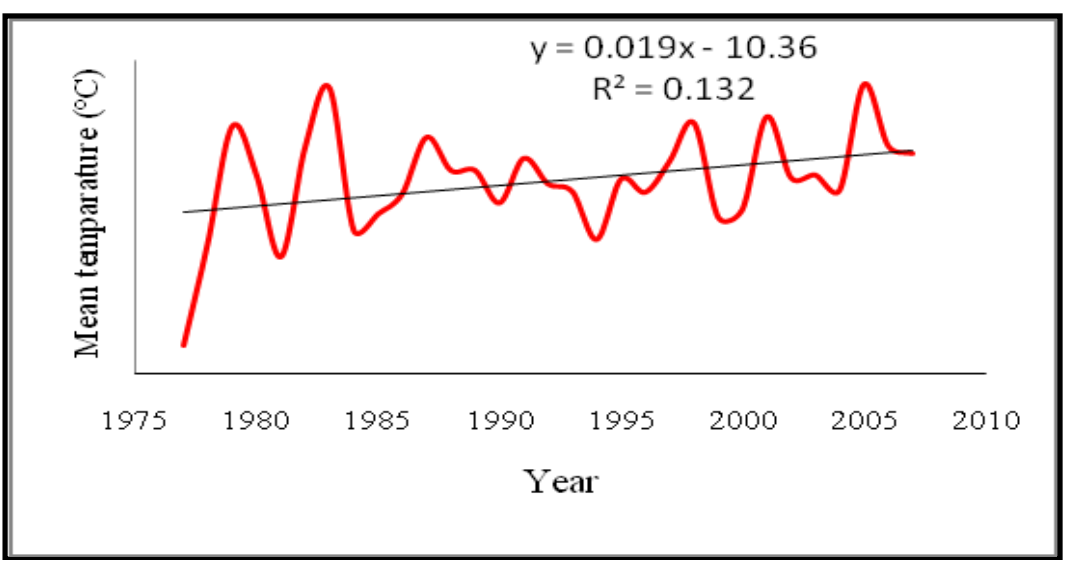

Fig .3. The time series of the mean temperature of the monsoon season .The thick line indicates the linear trend

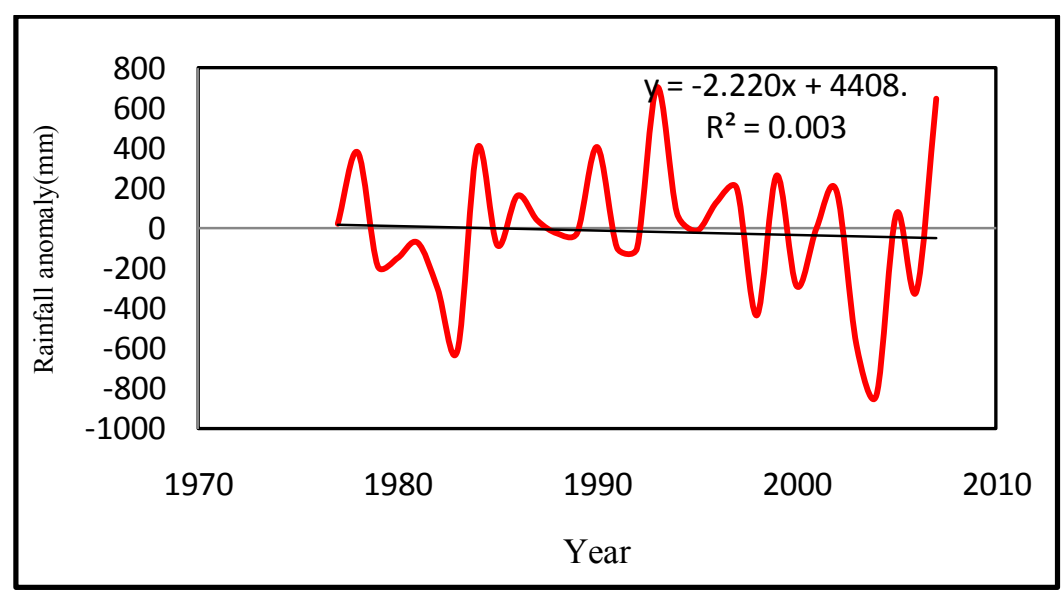

Fig.4. The distribution of monsoon rainfall (mm) for the period 1977-2007. The thick solid line indicates linear trend.

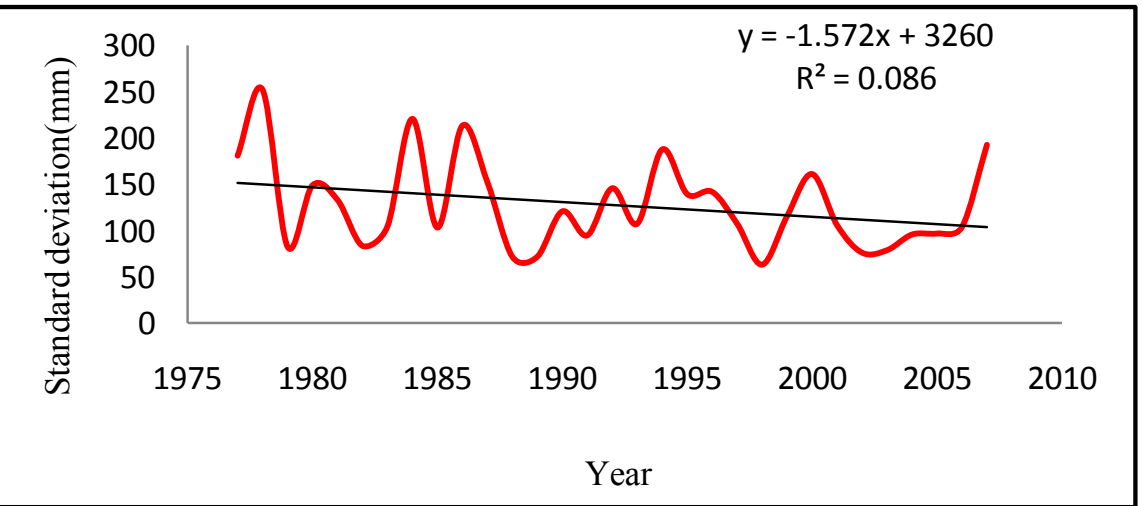

Fig .5. Standard deviation $(\sigma)$ of monsoon rainfall (1977- 2007). The Thick solid line shows the linear trend of standard deviation $(\sigma)$. 
Table 2: Calibrated genetic coefficients of MW-10 short season variety of rice in Aquacrop model

\begin{tabular}{|c|c|c|c|c|}
\hline Parameters & Definition & Unit & $\begin{array}{l}\text { Variables directly } \\
\text { influenced by the } \\
\text { parameter }\end{array}$ & Calibrated values \\
\hline $\begin{array}{l}\text { Development of } \\
\text { green canopy cover }\end{array}$ & $\begin{array}{c}\text { Soil surface covered by an } \\
\text { individual seedling at } \\
90 \% \text { recover }\end{array}$ & ( $\mathrm{cm}^{2} /$ plant $)$ & Crop phenology & $3.00-8.00$ \\
\hline Flowering & $\begin{array}{l}\text { Time from sowing to } \\
\text { flowering }\end{array}$ & $\begin{array}{l}\text { (growing } \\
\text { degree day) }\end{array}$ & Flowering date & $\begin{array}{c}\text { Time to } \\
\text { recover }+1000\end{array}$ \\
\hline Flowering & $\begin{array}{l}\text { Length of the flowering } \\
\text { stage }\end{array}$ & $\begin{array}{l}\text { (growing } \\
\text { degree day) }\end{array}$ & Harvest date & 300 \\
\hline $\begin{array}{l}Z \text { (development of } \\
\text { root zone) }\end{array}$ & $\begin{array}{l}\text { Time from sowing to } \\
\text { maximum rooting depth }\end{array}$ & $\begin{array}{c}\text { (growing } \\
\text { degree day) }\end{array}$ & Crop phenology & $1 \mathrm{~cm} /$ day \\
\hline $\mathrm{HI}_{0}$ & Referance harvest index & $(\%)$ & Harvest index & 35 \\
\hline $\mathrm{HI}_{0}$ & Building up of HI & $\begin{array}{c}\text { (growing } \\
\text { degree days) }\end{array}$ & Harvest index & $\begin{array}{l}\text { Until } 10 \% \text { green } \\
\text { canopy remains }\end{array}$ \\
\hline
\end{tabular}

Table 3: Statistics for comparison amongst simulated and measured values of crop yield

\begin{tabular}{|c|c|c|c|}
\hline Crop parameters & $\mathrm{R}^{2}$ & RMSE & ME \\
\hline Yield $(\mathrm{Kg} / \mathrm{ha})$ & 0.86 & 210 & 0.84 \\
\hline
\end{tabular}

RMSE=Root mean square error; ME=Model efficiency

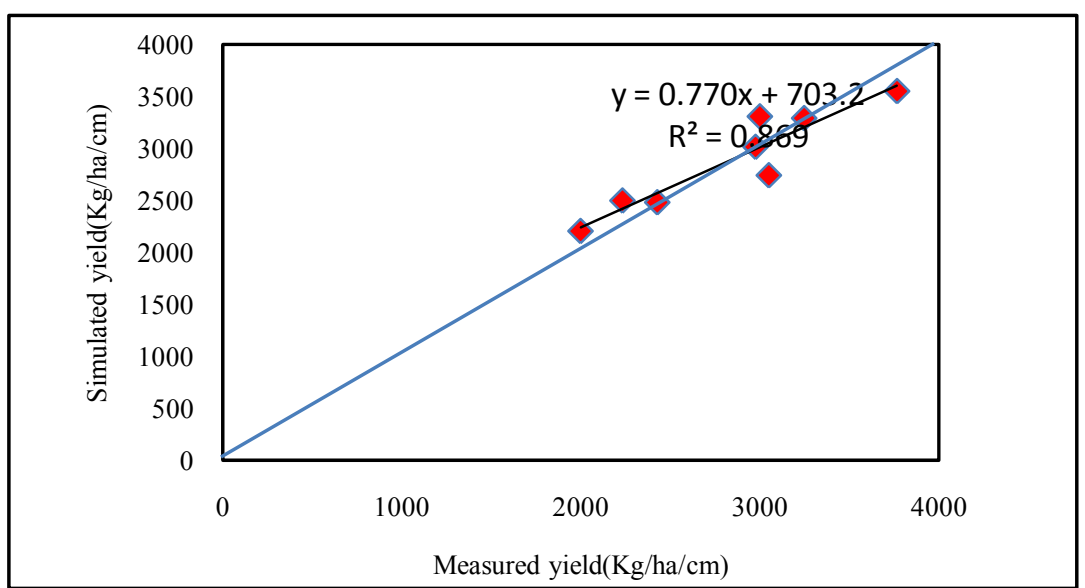

Fig .6.Comparison of measured and simulated yield of paddy during years 1998, 1999 and 2000 both in rain fed and irrigated conditions.

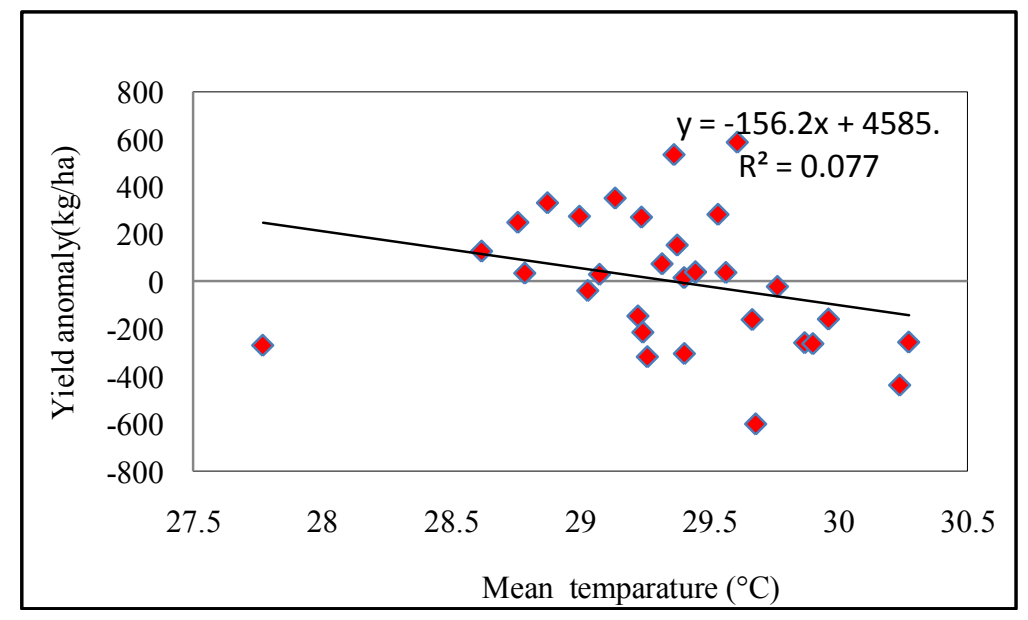

Fig.7. Scatter diagram of rain-fed MW-10 rice yield against mean temperature $\left({ }^{\circ} \mathrm{C}\right)$ for the monsoon period (Jun-Sep) 


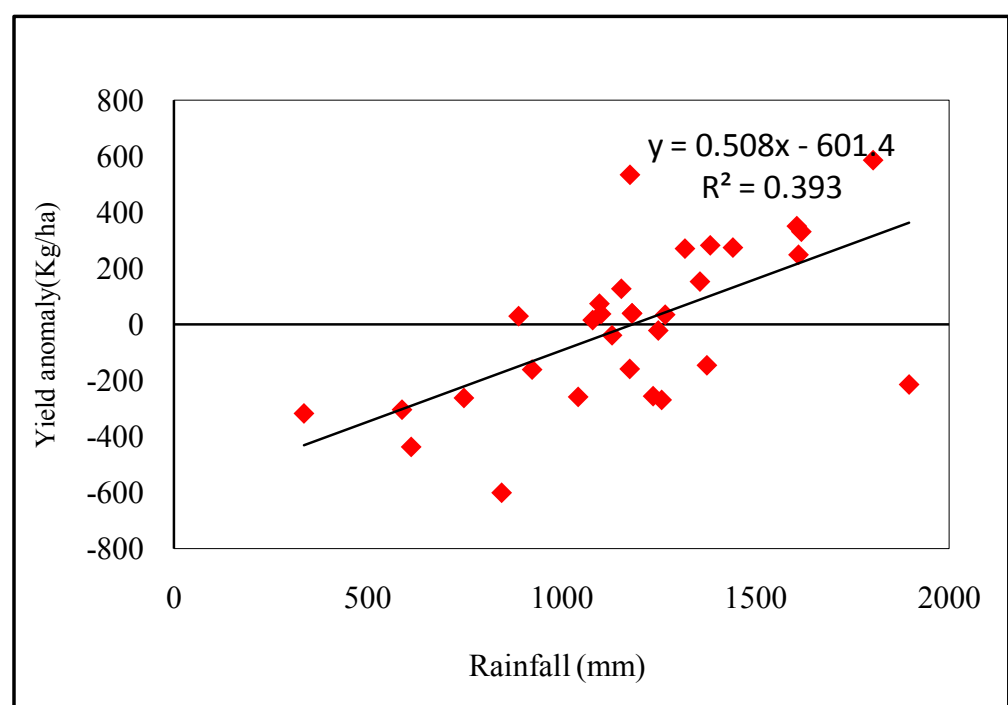

Fig.8. Scatter diagram of rain-fed MW-10 rice yield against rainfall (mm) for the monsoon period (Jun-Sep) at Kharagpur.

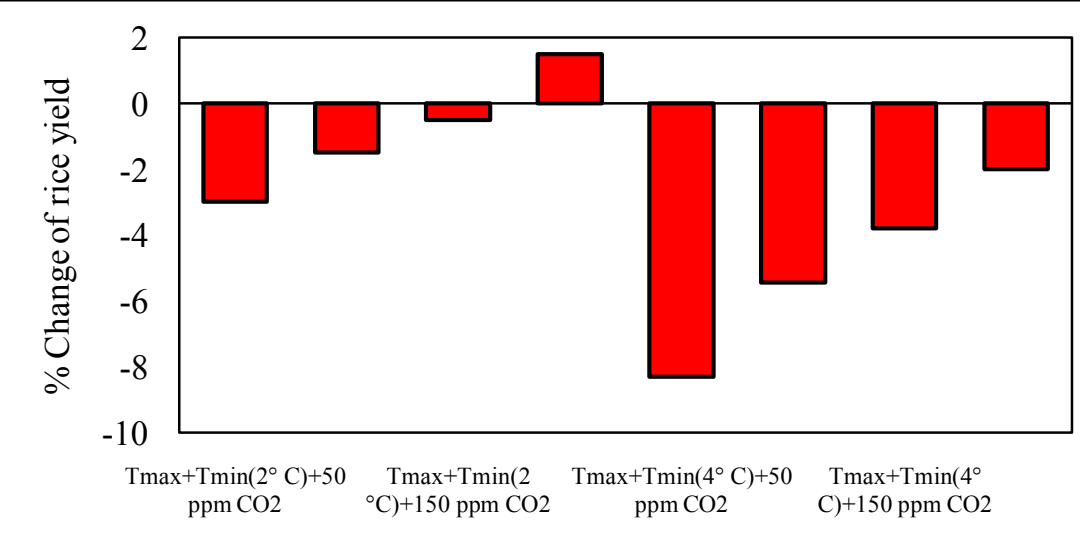

Fixed rise in $\mathrm{CO}_{2}$ concentration and temperature

Fig .9. Percentage of change of rice yield under various Climatic Scenarios in subtropical region.

Table 4. \% Change in yield under different incremental climate change scenarios in $\mathrm{kg} / \mathrm{ha}$.

\begin{tabular}{|c|c|c|c|c|}
\hline $\begin{array}{c}\text { Precipitation(mm) } \\
\mathrm{P}\end{array}$ & $\mathrm{T}$ (Temperature) & $\mathrm{T}+2^{\circ} \mathrm{C}$ & $\mathrm{T}+4{ }^{\circ} \mathrm{C}$ & Average \\
\hline $\mathrm{P}-10$ & $-16.57 \%$ & $-34.19 \%$ & $-37.67 \%$ & $-29.47 \%$ \\
\hline $\mathrm{P}-5$ & $-9.17 \%$ & $-26.28 \%$ & $-30.12 \%$ & $-21.85 \%$ \\
\hline $\mathrm{P}$ & - & -4.5 & -10.82 & $-7.66 \%$ \\
\hline $\mathrm{P}+5$ & $5.78 \%$ & $-7.42 \%$ & $-10.82 \%$ & $-4.15 \%$ \\
\hline $\mathrm{P}+10$ & $13.3 \%$ & $0.7 \%$ & $-3.32 \%$ & $3.56 \%$ \\
\hline
\end{tabular}

\section{CONCLUSION}

Many climatologists predict significant global warming in the coming decades due to increasing concentration of $\mathrm{CO}_{2}$ and other green house gases in the atmosphere. Higher temperature can negatively impact on crop production directly through heat stress. The yield of rice for the period 1977-2007 at Kharagpur had been derived using the weather parameters for the corresponding period. The analyzed time-series data showed that there was a decreasing trend of temperature and increasing trend of rainfall. Aquacrop v3.1 was used in the current study to simulate short season rice growth and to investigate the impact of climate change on yield response of rice at Kharagpur region. The grain yield of rice was influenced by a combination of fixed increments in $\mathrm{CO}_{2}$ concentration $(50 \mathrm{ppm}, 100 \mathrm{ppm}, 150 \mathrm{ppm}$ and $200 \mathrm{ppm})$, temperature (ambient $+2^{\circ} \mathrm{C},+4^{\circ} \mathrm{C}$ ) 
and rainfall variability $(\mathrm{P}, \mathrm{P}-10, \mathrm{P}-5, \mathrm{P}+5, \mathrm{P}+10)$. The simulations results suggest that maximum and minimum temperatures could significant affect on rice yield, and this effect could become more pronounced if temperatures rise in $4^{\circ} \mathrm{C}$. Sensitivity analysis indicates that crop model is sensitive to $\mathrm{CO}_{2}$ levels and has a positive impact on rice yield. Although higher $\mathrm{CO}_{2}$ levels in the future would balance the detrimental effects of increased temperatures to some extent but it would not be able to offset them. The model simulations also suggest that changes in rainfall pattern may also adversely affect on rice yield.

\section{REFERENCES}

[1] J. Ahmad. D. Alam and S. Haseen, Impact of climate change on agriculture and food security in India, IJAEB, 4(2), 2011 , $129-137$.

[2] L.S. Hingane, K. Rupa Kumar and B.V. Ramana Murty, Long term trends of surface air temperature in India.J.Climatol, 5, 1985,521-528.

[3] J.T. Houghton, Y. Ding, D.J. Griggs, M. Noguer, P.J. Linden, D. Xiaosu, K. Maskell, and C.A. Jonhnson, (eds), Climate change 2001. The scientific basis contribution of working group I to the third assessment report of the Intergovernmental panel on climate change (IPCC). Cambridge University Press, Cambridge, U.K, 2001.

[4] L.P. Amgain, N.R. Devkota, J. Timsina, and B. Singh, Effect of climate change and $\mathrm{CO}_{2}$ concentration on growth and yield of rice and wheat in Punjab:Simulations using CSM-CERES-RICE and CSM-CERES-WHEAT models. J.Inst.Agric.Anim. Sci., 27, 2006, $103-110$.

[5] J.V. Revadekar, and B. Preethi, Statistical analysis of the relationship between summer monsoon precipitation extremes and foodgrain yield over India. International Journal of Climatology, 31: n/a. doi: 10.1002/joc.2282,2011.

[6] M. Cooper, Concepts and strategies for plant adaptation research in rain fed lowland rice, Field Crops Res., 64(1-2),1999,13-34.

[7] S. Habtu, A. Araya, M.K. Hadgu, A. Kebede, and T. Dejene, Test of aquacrop model in simulating biomass and yield of water deficient and irrigated barley(Hordeum vulgare). Agriculture water management, 97,2010,1838-1846.

[8] L.K Heng, T.C. Hsiao, S. Evett, T. Howell, and P. Steduto, Validating the FAO Aquacrop model for irrigated and water deficient field maize. Agron. J., 101, 2009, 488-498.

[9] A.D. Quadir and F. Nazlee, The impact of climate variability on the yield of rain fed rice of Bangladesh. SAARC Meteorological Research centre (SMRC), Agargaon, Dhaka-1207, Bangladesh.2007.

[10] A.M. Choudhury, D.A. Quadir, S. Neelormi and A.U. Ahmed, Climate change and its impact on water resources of Bangladesh. Proceedings of the year end Workshop on 'Climate change and water resources in South Asia' held in Kathmandu, 7-9 January 2003, Proceedings published by APN and START,2003. 